\title{
Accreditation of Chemical, Criminal Investigation, and Other Laboratories
}

\author{
Hans-Jakob Ulrich* and Rolf Straub
}

\begin{abstract}
Scientific progress in chemical, medical, criminal investigation and in other chemical and physical laboratories demands an increasing number of complex testing procedures. Therefore, adequate quality control processes are required to guarantee the reliability of the test results. For the quality assurance in testing laboratories, inspection and certification bodies, the worldwide accreditation system establishes reliable and internationally recognised standards.
\end{abstract}

Keywords: Accreditation · Analytical chemistry · Criminal investigation · Laboratories · Quality control · Standards $\cdot$ Swiss Accreditation Service

\section{Accreditation is a National Duty}

The Swiss Accreditation Service (SAS) is the national accreditation body $(\mathrm{AB})$ of Switzerland. In 2006, SAS was incorporated into the State Secretary of Economic Affairs (SECO). It has been providing services since 1991. SAS is a member of the international accreditation network, which consists of several organisations, such as IAF (International Accreditation Forum, www.iaf.nu), ILAC (International Laboratory Accreditation Cooperation, www.ilac. org), EA (European Cooperation of Accreditation, www.european-accreditation. org) and others. On the European level, SAS is a full member of the MLA (Multilateral Agreement) of EA and therefore also in ILAC and IAF. SAS works in many projects, committees and working groups closely with other national accreditation bodies to further develop accreditation and harmonise requirements for assessment.
${ }^{\star}$ Correspondence: Dr. H.-J. Ulrich

Lead Assessor

Schweizerische Akkreditierungsstelle SAS

Lindenweg 50

$\mathrm{CH}-3003$ Bern-Wabern

Tel.: +41313234675

Fax: +41313233 510

E-mail: hans-jakob.ulrich@sas.ch

\subsection{Accreditation is a Powerful Instrument for Quality Control}

Accreditation fulfils an important function in the economy today. It ensures that conformity assessment bodies (CABs) are monitored based upon internationally recognised standards. This enables the international recognition of test reports and certificates issued by the accredited CABs. SAS accredits the following types of CABs: Testing and calibration laboratories of all types, inspection and certification bodies for persons, for management systems (including e.g. environmental, food and workplace safety management systems), and for products. Recently, SAS also performs accreditation of producers of certified reference materials. For the accredited conformity assessment bodies, the accreditation label certifies that:

- The staff is adequately trained to perform a particular task and is competent to understand and apply the requirements in the technical field of interest as well as able to estimate the risks involved in its work covered by the individual scope of accreditation.

- The conformity assessment body is equipped with adequate infrastructure and that the technical procedures are fit for purpose and well documented.

- The conformity assessment body applies an efficient quality management system and meets the requirements of the relevant international standards during the validity of its accreditation. To assess a laboratory or a $\mathrm{CAB}$, internationally recognised standards are applied: The ISO 17000 series of standards is generally used as accreditation standards by the accreditation body regulating the basic requirements for management system, technical requirements and is used to assess competence in the body. On the technical level the accredited body can apply a large number of technical standards, e.g. EN-, ISO-, SIA-, DIN-standards, among many others. The body can also apply after proof of competence, general acceptance in the technical field and confirmation of systematic application by its staff's own appropriately validated procedures. Periodic surveillance assessments ensure that the accredited bodies maintain their level of technical knowledge and of quality.

Therefore, accreditation provides the confidence to third parties that the results issued by accredited laboratories or conformity assessment bodies are reliable. However, the accreditation body does not take direct responsibility for the work provided by the accredited $\mathrm{CAB}$ and the outcome of it. The reliability of presented results is especially important in areas regulated by legal requirements, such as in the field of epizootic diseases (animal diseases), in forensic investigation (e.g. DNA typing of swabs and traces) or in the monitoring of food quality (e.g. investigations of foodstuffs and drinking water) and of environmental standards. Accreditation can provide a competitive advantage and facilitates access to international markets, with the aim of "tested or certified once, accepted everywhere".

In order to ensure the quality of the tests, a laboratory is accredited according to the international standard ISO/IEC 17025. ${ }^{1]}$ The requirements considering the management system are very much congruent with those of the well-known standard ISO 9001:2008[2] used in management system certification. In addition, the standard ISO/IEC 17025 regulates the requirements with respect to the technical knowhow allowing SAS to approve organisational and technical competence. The essential requirements of the standard EN ISO/IEC 17025 are: 
- The accredited body (AB) must be an entity which can be held legally responsible.

- The AB has to maintain a quality management system which covers all quality-relevant processes.

- The management system contains processes of continuous improvement (which includes procedures for corrective and preventive actions, internal audits, management reviews, among others).

- Relations with clients, providers and subcontractors are regulated.

- Document control.

- Control of records.

- Adequate education and continuous training of staff at all levels.

- Infrastructure and equipment of the AB must be safe and fit for purpose.

- Sampling (where applicable) and handling procedures of test materials must be defined.

- Traceability and trackability of the measurements.

- Adequate validation and documentation of the test methods (this includes all relevant data about the test procedures, such as measuring range, detection limits, determination limits, uncertainty of measurement, among others).

- Systematic quality monitoring (internal monitoring as well as external controls, such as Proficiency Testing and/ or interlaboratory comparisons).

- Documentation of the test results, confidentiality of client data.

\section{Accreditation of Chemical and Industrial Laboratories}

Today, most chemical and environmental laboratories are accredited as testing and/or inspection bodies. The relevant standards for these types of accreditation are EN ISO / IEC 17025 and EN ISO / IEC 17020, respectively. ${ }^{[1,3]}$ General industrial production is covered by ISO 9001.[2]

In the widespread area of chemistry, let us have a look at three examples of great importance, with special focus on the aspects of accreditation:

- Monitoring of drinking water quality

- Noble metal analysis

- Production of reference materials

\subsection{Monitoring the Quality of Drinking Water in Basel}

The Industrial Enterprises of Basel (IWB) supply natural gas, electricity and drinking water to the city. For the quality control of the drinking water, the production plant has been running its own laboratory since 1913. In 1964, IWB established an artificial infiltration of Rhine water into the ground water in the Langen
Erlen area. The infiltration area consists of 14 different sites located in the forested territory, with a total area of approximately 220'000 square meters. During the slow infiltration through natural ground, the water is purified by adsorption processes and microbiological activities in the soil. In order to allow the microorganisms to recover, the infiltration areas are kept dry periodically. The infiltration has proved to be very efficient; no significant loss of efficiency has been reported since 1964. The ground water is then collected in different ground water fountains in the Langen Erlen area.

The water quality is monitored carefully. Bacteriological tests as well as chemical monitoring ensure that the drinking water is free of pollutants. In 1999, IWB obtained the accreditation of its water laboratory as a testing laboratory as well as an inspection body. The IWB was the first water supplier in Switzerland to obtain an accreditation according to the international standards ISO 17020 (inspection) and ISO 17025 (testing). The testing laboratory uses modern methods to analyse the chemical parameters of the drinking water, such as:

- Alkalinity

- Calcium-, magnesium- and total hardness

- Dissolved organic carbon (DOC)

- Nitrate

- Heavy metals

- Organic trace compounds

The laboratory uses analytical procedures such as ICP-AES (Inductively Coupled Plasma Atomic Emission Spectrometry), HPLC (High Pressure Liquid Chromatography) and GC (Gas Chromatography) coupled with different detection techniques. Bacteriological test are performed according to international standards.

The laboratory also performs tests for private clients as long as these are not in contradiction with its municipality work. The inspection body inspects the infrastructure of the water supplier, especially the reservoir sites, the onsite monitoring instruments and, generally, the maintenance and the status of the water plant equipment. For this purpose, specially trained inspectors of the IWB staff periodically inspect the infrastructure. The inspectors are also trained to perform onsite measurements ( $\mathrm{pH}$, electrolytic conductivity, oxygen saturation) and to take samples for chemical and biological analyses. Furthermore, the IWB inspectors can offer their services to other communities, especially counselling and inspections.

The inspection body (IB) of IWB Basel is accredited according to the standard EN ISO/IEC 17020. This standard also contains the general requirements for manage- ment system (MS), as well as the special requirements for IBs, such as:

- Independence and impartiality of the IB

\section{- Staff training}

- Documented inspection procedures

- Handling procedures for samples and items of the inspections

- Control of records

- Documentation of the inspection results, confidentiality of client data

Compliance with the requirements of the standards EN ISO/IEC 17020 and EN ISO/IEC 17025 guarantees that the test methods and inspection procedures applied by the IWB Basel are fit for purpose and, thus, fulfil the requirements of the clients.

\subsection{Noble Metal Analysis}

The Swiss canton Ticino is an important spot on the world map of noble metal refineries. About $40 \%$ of the world production of the raw metals and metal ores of gold, silver, platinum and palladium are processed in one of the three noble metal refineries in the southern part of the canton. One of these companies, Valcambi S.A., processed more than 600 tonnes of noble metals in 2004. The company is internationally recognised as a 'London Good Delivery Refiner'. Due to the high value of the processed materials, very strict quality regulations and safety restrictions are in force. As an example, all persons leaving the firm area must pass through metal detectors.

For the quality monitoring, Valcambi S.A. runs its own test laboratory, which is accredited according to the standard EN ISO / IEC 17025. The main tasks of the laboratory are:

- Quality monitoring of raw materials

- Production control

- Determination of noble metal contents in alloys and semi products

- Monitoring of product quality

Specially trained personal apply internationally recognised test methods. Modern facilities and equipment are used by the test laboratory, such as XRF-spectroscopy and ICP-AES. For the high precision determination of metal contents, gravimetric methods are applied as well. Due to the high values of the products, the measurements must have a very high precision and accuracy. Therefore, the metrological traceability of the analytical result has to meet the highest standards. Thus, the assessment teams of the SAS put most emphasis on the technical knowledge of the staff, the validation and documentation of the testing procedures and on the metrological traceability of the measurements as well as on the control of the records. 
The quality control also includes measurements with tested reference materials and inters laboratory comparisons organised by the noble metal laboratory of the Swiss Financial Department. The accreditation ensures that the test laboratory provides reliable test results, which in turn are the basis of the confidence in the quality of the precious products.

\subsection{Production of Certified Reference Materials}

Since 2007, the SAS has been providing an accreditation service for producers of certified reference materials. So far, accreditation bodies offer this type of accreditation in the following European countries: Belgium, Denmark, United Kingdom and Switzerland. In 2000, the ILAC decided that this new accreditation type should be based upon the ISO Guide 34 in combination with the standard EN ISO / IEC 17025.[1,4] Producers of certified reference materials (CRP) have to implement the following main procedures into their management system (MS):

- Planning of the production. This includes testing, monitoring and characterising the starting materials, planning production and quality monitoring procedures.

- Definition of the tests for homogeneity and stability. These tests should guarantee that the products meet the quality criteria specified in the certificates during the entire lifetime.

- Characterisation of the reference materials and determination of the specific property data. Analytical procedures must be defined to determine all significant data of the reference material. Any analytical test procedures must fulfil the requirements of the standard EN ISO/IEC 17025.

- Assignment of property values and their uncertainties. The procedures shall meet the requirements of the ISO Guide $35,{ }^{[5]}$ i.e. adequate statistical methods should be used to determine the property values and their uncertainties.

- Validation of the property values and the issuing of the certificates. The certificates have to contain all information stated in the ISO Guide 31.[6]

- Directions for the maintenance and storage of the reference materials. These instructions must be available to the clients.

- Transport and distribution services for the clients. After purchase services such as consulting shall be available for the clients.

In 2007, Sigma-Aldrich GmbH became the first company in Switzerland to be accredited as CRP. Sigma-Aldrich $\mathrm{GmbH}$ produces organic and inorganic solutions of reference materials ( $c f$. Wüthrich and Weber, this issue $\left.{ }^{[7]}\right)$. The accreditation assessment covered all the procedures mentioned above, the most crucial elements are:

- The technical knowhow of the staff, the definition of the responsibilities.

- Correct implementation and documentation of the production and quality monitoring procedures

- Adequate infrastructure and equipment for the production and for the monitoring of the product quality.

- The metrological traceability of all measurement results and the values for the calibration materials involved.

- Adequate procedures of evaluating and assigning the property values to the reference materials, including the expanded uncertainty values.

- The responsibilities for the validation and for the edition of certificates have to be in agreement with the requirements of the ISO Guides 34 and 31.

Compliance with the requirements of the accreditation standards guarantees that the product characterisations given in the certificates are correct and that they can be maintained over the entire lifetime of the products.

\section{Forensic Investigation}

The number of accredited forensic laboratories of forensic university institutes and of Swiss police forces has significantly increased over the past years. Accreditation in the field of forensic was first initiated in 2000 by new federal laws in the field of DNA trace analysis and paternity testing for forensic purposes. ${ }^{[8-10]}$ In Switzerland, the following forensic laboratories and/or inspection bodies have obtained accreditation by SAS:

- Forensic genetic laboratories of all Swiss forensic institutes.

- Forensic toxicology of some Swiss forensic institutes (e.g. Institut für Rechtsmedizin in Basel).

- Scientific Service of the Stadtpolizei Zürich: forensic drug analysis.

- Scientific Research Services of the Stadtpolizei Zürich: forensic investigations/analysis of explosives.

- Department of criminal investigation of the Kantonspolizei Zürich: forensic tests on documents and handwritings to confirm authenticity or to proof falsifications of different kind.

- Forensic services of the police of the canton St. Gallen in the field of testing: chemical, physical and technical tests methods in the context of general forensic or crime scene investigation (CSI).
- Kantonspolizei Luzern: inspection body for CSI activities.

Currently, other forensic laboratories or CSI units of Swiss police forces are in the process of obtaining the accreditation according to the standards ISO/IEC 17025 and/or ISO/IEC 17020 for different forensic activities.

The spectrum of chemical and physical tests applied in forensic is extremely widespread. Modern test methods are adapted for the special purposes. It is not unusual that different practical aspects have to be considered and empirical tests are necessary to better understand what really happened on a crime scene. This requires a high level of technical knowledge and individual practical experience that are checked during assessment on-site.

Technical standards and legal requirements are also taken into account for the definition of the testing and/or inspection procedures. Very sophisticated test methods require special knowledge of complex processes. The sampling techniques in the forensic field are sometimes special and thus extremely challenging and never seen by specialists as a pure routine task. Therefore, proper assessment of the technical capability performed by peers with established reputations is essential to grant accreditation in this domain, last but not least to guarantee a so-called 'court proof system' in general not open to question by the defendant party. To illustrate the importance of reliable, validated and accurate test methods the following example cited in the paper of Finkelstein is given.[11]

When the physical markings of a fired bullet recovered from a crime scene are too mutilated for visual comparison or the firearm used in the crime is not recovered, the bullet can be compared with other bullets associated with a suspect by its elemental composition. When a crimescene bullet contains the same analytical elemental contents (i.e. match in composition) as the bullets from known cartridges, a single source for these bullets cannot be excluded. During the manufacturing processes, thousands of lead specimens (bullets and bullet cores) are produced with analytically indistinguishable compositions. However, those lead specimens that share the same composition are generally packaged within the same box of cartridges, or in boxes of cartridges of the same calibre and type at the same manufacturing plant, on or about the same date. When the differences in element concentrations are small but analytically significant, a comparative examination can be used to differentiate among bullets made of different alloys or to exclude a single source for bullets of the same alloy. 


\section{Conclusion and Summary}

Efficient and adequately defined testing and inspection procedures ensure that the quality of the test and inspection reports meets the requirements of the clients. The accreditation is a powerful instrument of quality management, including also the technical knowhow and the specific properties of the test procedures. Thus, the accreditation covers all the factors which are relevant for the quality of the test and inspection results. By the compliance with the relevant accreditation standards, the reliability of these results can be significantly improved.

\section{Acknowledgements}

The authors are grateful for the support by the Swiss Accreditation Service SAS.

Received: July 28, 2009

[1] ISO/IEC 17025: 2005, 'General requirement for the competence of testing and calibration laboratories'

[2] ISO 9001: 2008, 'Quality management systems - Requirements'
[3] ISO/IEC 17020: 1998, 'General criteria for the operation of various types of bodies performing inspection'.

[4] ISO Guide 34: 2000, 'General requirements for the competence of reference material producers'.

[5] ISO Guide 35: 2006, 'Reference materials General and statistical principles for certification'.

[6] ISO Guide 31: 2000, 'Reference materials Contents of certificates and labels'.

[7] J. Wüthrich, M. Weber, Chimia 2009, 63, 632.

[8] SR 363, Bundesgesetz über die Verwendung von DNA-Profilen im Strafverfahren und zur Identifizierung von unbekannten oder vermissten Personen (DNA-Profil-Gesetz) vom 20. Juni 2003 (Stand am 28. Dezember 2004).

[9] SR 363.1, Verordnung über die Verwendung von DNA-Profilen im Strafverfahren und zur Identifizierung von unbekannten oder vermissten Personen vom 3. Dezember 2004 (Stand am 5. Dezember 2008).

[10] SR 363.11, Verordnung des EJPD über die Leistungs- und Qualitätsanforderungen für forensische DNA-Analyselabors (DNAAnalyselabor-Verordnung EJPD) vom 29. Juni 2005 (Stand am 26. Juli 2005).

[11] B. Levin, M. O. Finkelstein, J. Law and Policy 2005, 13(1), 119. 